\title{
PENINGKATAN KOMPETENSI ISLAMI BERWAWASAN LINGKUNGAN MAHASISWI UNIVERSITAS MUHAMMADIYAH PALANGKARAYA MELALUI KULIAH KERJA NYATA
}

\section{(Improvement of Islamic Competency in Universitas Muhammadiyah Palangkaraya Through Community Service Program)}

\section{ADY FERDIAN NOOR, BULKANI}

\author{
Program Studi Pendidikan Guru Sekolah Dasar (PGSD) Fakultas Keguruan dan Ilmu Pendidikan \\ Universitas Muhammadiyah Palangkaraya \\ Jl. RTA Milono Km 1,5 Palangka Raya, Kalimantan Tengah 73111 \\ Email: ady_noor@yahoo.com dan BulkaniArdiansyah@gmail.com
}

\begin{abstract}
Student competence is a skill that must be developed through Community Service Program (KKN). KKN Muhammadiyah University of Palangkaraya carried out according to the Master Plan Development of PkM and modified with the Motto of Muhammadiyah University of Palangkaraya: "The Green Islamic Campus" Islamic Campus with the Environment and with focus on PKM activities conducted by Student. Competence is important to keep in mind.

McAnhan (1981) argues that competence is a knowledge, skill, and capability possessed by someone who has become a part of himself to color his cognitive, affective, and psychomotoric behavior (Sanjaya, 2008). PKM this time at the Community Service Program in the business charity Muhammadiyah University of Palangkaraya led to the fact that women can carry out the work normally done by men. The activities include physical activity helping to create a yard with paving, cementing, sifting sand, planting trees, cleaning sewers and trash, sweeping; non-physical activities teaching or dancing or giving lectures on the ideal family.

Women are very active role and really take advantage of all the knowledge and energy in improving competence while maintaining the limit etiquette. The objective of KKN is to create students who have the competence to be able to work in terms of supporting the greening movement and keep dressing and behaving in an Islamic way.
\end{abstract}

Keywords: Competence, Islami, Environment, KKN

\begin{abstract}
Abstrak
Kompetensi mahasiswa merupakan kemampuan yang harus dikembangkan melalui Kuliah Kerja Nyata (KKN). KKN Universitas Muhammadiyah Palangkaraya dilaksanakan sesuai Rencana Induk Pengembangan PkM dan dimodifikasi dengan Motto Universitas Muhammadiyah Palangkaraya: "The Green Islamic Campus" Kampus Islami yang Berwawasan Lingkungan dan dengan difokuskan pada kegiatan PKM yang dilaksanakan oleh Mahasiswi. Kompetensi merupakan hal yang penting untuk terus diperhatikan.

Mc Ashan (1981) mengemukakan bahwa kompetensi adalah suatu pengetahuan, keterampilan, dan kemampuan atau kapabilitas yang dimiliki oleh seseorang yang telah menjadi
\end{abstract}


bagian dari dirinya sehingga mewarnai perilaku kognitif, afektif, dan psikomotoriknya (Sanjaya, 2008). PKM kali ini pada saat Kuliah Kerja Nyata di lingkungan amal usaha Universitas Muhammadiyah Palangkaraya memunculkan bahwa perempuan pun dapat melaksanakan pekerjaan yang biasa dikerjakan oleh laki-laki. Kegiatan itu meliputi Kegiatan fisik membantu membuat halaman dengan paving, menyemen, mengayak pasir, menanam pohon, membersihkan selokan dan sampah, menyapu; kegiatan non fisik mengajar mengaji atau menari atau memberikan ceramah tentang keluarga yang ideal.

Perempuan sangat berperan aktif dan benar-benar memanfaatkan semua ilmu dan tenaga dalam meningkatkan kompetensi dengan tetap menjaga batas etika pergaulan. Tujuan dari KKN tersebut menciptakan mahasiswi yang mempunyai kompetensi mampu bekerja dalam hal mendukung gerakan penghijauan dan tetap berpakaian dan berperilaku islami.

Kata Kunci: Kompetensi, Islami, Lingkungan, KKN

\section{PENDAHULUAN}

Tri dharma perguruan tinggi wajib dilaksanakan oleh setiap perguruan tinggi. Salah satu tri dharma perguruan tinggi yaitu pengabdian kepada masyarakat. Pengabdian kepada masyarakat dilaksanakan berbasis kepada kepentingan dan kebutuhan masyarakat sehingga mampu meningkatkan kesejahteraan masyarakat. Salah satu program pengabdian kepada masyarakat yaitu Kuliah Kerja Nyata (KKN). KKN yang merupakan mata kuliah yang harus ditempuh oleh mahasiswa. KKN diharapkan mampu memanfaatkan ilmu pengetahuan dan teknologi mahasiswa. Ilmu pengetahuan dan teknologi merupakan kompetensi yang didapat oleh mahasiswa selama menempuh perkuliahan sesuai harapan dari UURI No 20 Tahun 2003 tentang Sistem Pendidikan Nasional dan UURI No 12 Tahun 2012 tentang Pendidikan Tinggi.

Universitas Muhammadiyah Palangkaraya (UM Palangkaraya) melaksanakan KKN terintegrasi dengan Motto "Green Islamic Campus" yang artinya Kampus Islami berwawasan Lingkungan. Hal tersebut terintegrasi dengan KKN artinya pelaksanaan KKN harus berpedoman pada Buku Pedoman/Panduan Pelaksanaan Green Islamic Campus. Ditambahkan lagi bahwa UM Palangkaraya melaksanakan Catur
Dharma yaitu menambahkan indikator KeIslaman dan Ke-muhammadiyahan. Hal itu mengindikasikan bahwa Lembaga Penelitian dan Pengabdian Kepada Masyarakat (LP2M) sebagai lembaga pelaksana kegiatan KKN wajib berpedoman pada Rencana Induk Pengembangan Pengabdian Kepada Masyarakat dan Buku Pedoman/Panduan Pelaksanaan Green Islamic Campus.

Kuliah Kerja Nyata adalah bagian integral dari proses pendidikan yang mempunyai ciri-ciri khusus, karenanya sistem penyelenggaraannya memerlukan landasan idiil yang secara filosofis akan memberikan gambaran serta pengertian yang utuh tentang apa, bagaimana serta untuk apa KKN itu diselenggarakan. Landasan idiil secara filosofis akan memberikan petunjuk serta mengendalikan pola pikir dan pola tindakan dalam setiap proses penyelenggaraan $\mathrm{KKN}$ yang pada gilirannya akan membedakan dari bentuk-bentuk kegiatan lain yang bukan KKN. Kuliah Kerja Nyata (KKN) sekurangkurangnya mengandung lima aspek yang bernilai fundamental dan berwawasan filosofis yang tidak dapat dipisahkan antara satu dengan yang lain, yaitu 1) Keterpaduan Catur Dharma Perguruan Tinggi; 2) Pendekatan Interdisipliner dan Komprehensif; 3) Lintas Sektoral; 4) Dimensi yang Luas dan Kepragmatisan; dan 
5) Keterlibatan Masyarakat secara Aktif (Tim LP2M, 2016).

Kompetensi mahasiswa merupakan kemampuan yang harus dikembangkan melalui KKN. Kuliah Kerja Nyata Universitas Muhammadiyah Palangkaraya dilaksanakan sesuai Rencana Induk Pengembangan PkM dan dimodifikasi dengan Motto Universitas Muhammadiyah Palangkaraya: "The Green Islamic Campus" Kampus Islami yang Berwawasan Lingkungan dan dengan difokuskan pada kegiatan PKM yang dilaksanakan oleh Mahasiswi. McAshan (1981) mengemukakan bahwa kompetensi itu adalah:

"...A knowledge, skills, and abilities or capabilities that a person achives, which became part of his or her being to the exent he or she can satisfatorily perform particular cognitive, afective, and psychomotor behaviors" (Sanjaya, 2008)

Artinya Kompetensi adalah suatu pengetahuan, keterampilan, dan kemampuan atau kapabilitas yang dimiliki oleh seseorang yang telah menjadi bagian dari dirinya sehingga mewarnai perilaku kognitif, afektif, dan psikomotoriknya. PKM yang kecenderungannya mahasiswi pasti kebagian mengerjakan pekerjaan yang sesuai kodratnya misalnya menyiapkan minuman dan makanan, memasak, menyapu tetapi kegiatan PKM kali ini pada saat Kuliah Kerja Nyata di lingkungan amal usaha Universitas Muhammadiyah Palangkaraya memunculkan bahwa perempuan pun dapat melaksanakan pekerjaan yang biasa dikerjakan oleh lakilaki. Kegiatan itu meliputi Kegiatan fisik membantu membuat halaman dengan paving, menyemen, mengayak pasir, menanam pohon, membersihkan selokan dan sampah, menyapu; kegiatan non fisik mengajar mengaji atau menari atau memberikan ceramah tentang keluarga yang ideal. Hal tersebut dilakukan dengan tetap berpakaian dan berperilaku secara islami. Artinya perempuan sangat berperan aktif dan benar-benar memanfaatkan semua ilmu dan tenaga dalam meningkatkan kompetensi dengan tetap menjaga batas etika pergaulan. Tujuan dari KKN tersebut menciptakan mahasiswi yang mempunyai kompetensi mampu bekerja dalam hal mendukung gerakan penghijauan dan tetap berpakaian dan berperilaku islami.

\section{METODE PELAKSANAAN}

Waktu pelaksanaan KKN bulan April s/d Juni dan September s/d Desember. Tempat Pelaksanaan Kota Palangka Raya.

Sasaran kegiatan yaitu penghijauan di pinggir selokan Universitas Muhammadiyah Palangka Raya Kampus Mahir Mahar dan Membangun halaman SD Muhammadiyah Cilik Riwut Km 8 kota Palangka Raya.

Metode kegiatan penghijaun adalah melalui pemilihan tanaman yang cocok untuk ditanam di pinggir-pinggir selokan Universitas Muhammadiyah Palangka Raya Kampus Mahir Mahar dan membangun halaman dengan memberikan tanah pada rawa2

Solusi yang ditawarkan yaitu penghijauan dilakukan dengan serentak dan bersamasama semua kelompok agar waktu tanam sama dan pemilihan tanaman sesuai dengan karakteristik tanah dan disiram secara terus menerus selama dua minggu dan membangun halaman dengan menggunakan tanah urug supaya mencapai kekerasan tanah halaman yang diinginkan mulai dari menimbun, memadatkan, dan merapikan.

\section{HASIL DAN PEMBAHASAN}

Kompetensi Islami yaitu mereka mahasiswi berpakaian rapi dan bergaul sesuai etika pergaulan selama melaksanakan pekerjaan 
penanaman pohon secara serentak dan membuat halaman. Hal ini mengindikasikan bahwa pola islami dalam berpakaian dan pergaulan selama pelaksanaan program pekerjaan ditaati oleh mahasiswi sehingga pekerjaan tidak ada hambatan yang berarti dan berjalan sesuai dengan target yang telah ditetapkan oleh LP2M. Buku Panduan Program Green Islamic Campus sudah dijalankan dengan baik dalam pelaksanaan program-program kegiatan KKN. Rata-rata jumlah perempuan dalam setiap kelompok adalah $80 \%$.

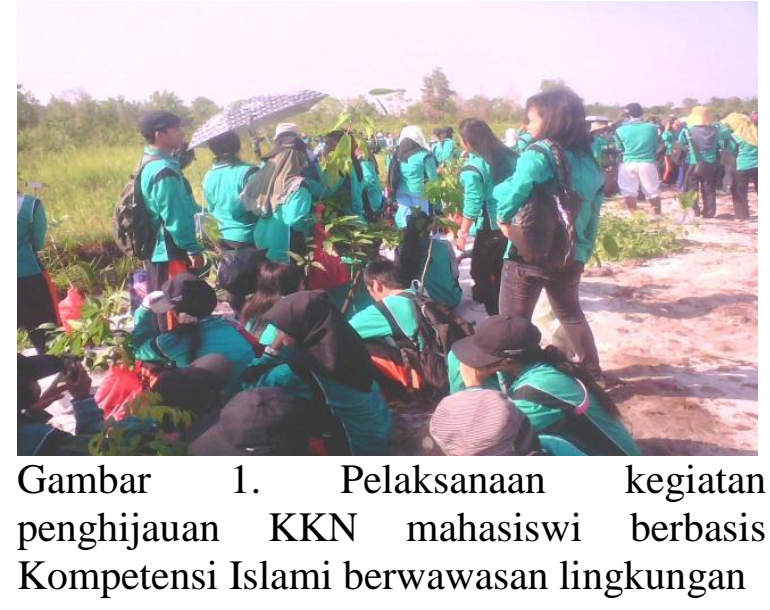

Kompetensi Berwawasan Lingkungan yaitu mampu mencintai penghijauan, melaksanakan reboisasi, menyayangi pohon dan tanaman. Hal tersebut dilaksanakan dengan menanam pohon secara serentak dan bersama2 sehingga diharapkan tumbuh secara bersama2. Penghijauan pada sepanjang parit dilaksanakan bertujuan untuk memperkuat tanah yang ada dipinggiran sehingga mampu menopang tanah agar tidak jatuh ke saluran air. Hal tersebut juga untuk menambah keindahan pinggiran jalan pada sisi kanan kiri sehingga menimbulkan kesejukkan dan keteduhan bagi pengguna jalan.

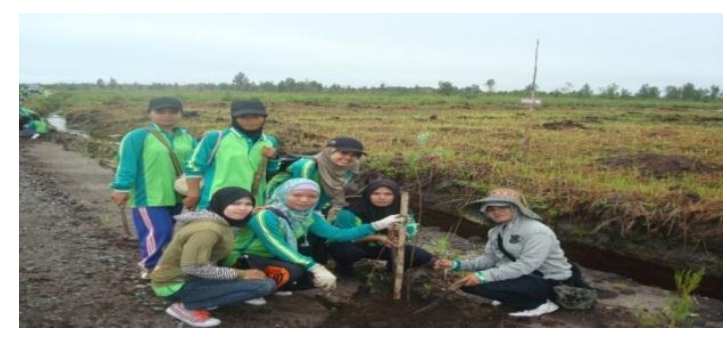

Gambar 2. Penanaman Pohon dipinggiran saluran air di kampus 2 UM Palangkaraya

Pengawasan aturan berpakaian islami dan tata pergaulan islami tidak hanya dilaksanakan pada saat perkuliahan baik didalam dan diluar kelas. Dalam hal ini KKN merupakan salah satu mata kuliah yang wajib ditempuh oleh mahasiswa. Dilihat selama pelaksanaan KKN semua mahasiswa mematuhi tata cara berpakaian dan tata cara pergaulan sehingga tidak terjadi hal-hal yang berindikasi pelecehan dan kekerasan seksual. Adanya mahasiswi non muslim juga menjadi salah satu berkembangannya toleransi beragama yaitu saling menghormati dalam berpakaian. Pelaksanaan KKN merupakan wujud nyata bahwa Islami yang ada pada slogan Green Islamic Campus sudah dijiwai dan dipahami oleh semua sivitas akademika Universitas Muhammadiyah Palangkaraya dan diimplementasikan pada kegiatan kehidupan sehari-hari.

Penghijauan yang telah dilaksanakan mampu menjadi salah satu solusi untuk membantu pengembangan pembangunan kawasan pendidikan yang hijau yang dicanangkan oleh pemerintah kota Palangka Raya. Selain itu penanaman pohon palm di pinggiran saluran air/selokan di jalan2 kampus 2 memperkuat tanah yang ada disekitar pinggiran saluran air tersebut. Pada akhirnya kalau sudah besar akan menjadi pelindung bagi pengguna jalan dan mampu mengurangi polusi asap kendaraan serta menjadi sirkulasi oksigen yang baik. 


\section{KESIMPULAN}

Kegiatan kompetensi Islami bagi mahasiswi mencakup tata cara berpakaian dan tata cara pergaulan selama pelaksanaan KKN dapat dilaksanakan dengan baik dengan adanya toleransi.

Kegiatan kompetensi berwawasan meningkatkan kepedulian mahasiswi untuk dapat berperan aktif dalam pembangunan kota Palangka Raya dan reboisasi untuk kampus 2 UM Palangkaraya..

\section{REFERENSI}

Bulkani, 2016, Buku Panduan Pelaksanaan The Green Islamic Campus, Palangka Raya:

UM Palangkaraya

Sanjaya, 2015, Pembelajaran dalam

Implementasi Kurikulum Berbasis

Kompetensi, Jakarta: Kencana

Tim, 2017, Buku Panduan KKN LP2M, Palangka Raya: LP2M Universitas

Muhammadiyah Palangkaraya

Tim, 2016, Buku RIP UM Palangkaraya, Palangka Raya: Universitas Muhammadiyah Palangkaraya 